\title{
Alcohol consumption and mortality from all causes, coronary heart disease, and stroke: results from a prospective cohort study of Scottish men with 21 years of follow up
}

\author{
Carole L Hart, George Davey Smith, David J Hole, Victor M Hawthorne
}

\begin{abstract}
Objectives To relate alcohol consumption to mortality.

Design Prospective cohort study.

Setting 27 workplaces in the west of Scotland.

Participants 5766 men aged 35-64 when screened in 1970-3 who answered questions on their usual weekly alcohol consumption.
\end{abstract}

Main outcome measures Mortality from all causes, coronary heart disease, stroke, and alcohol related causes over 21 years of follow up related to units of alcohol consumed per week.

Results Risk for all cause mortality was similar for non-drinkers and men drinking up to 14 units a week. Mortality risk then showed a graded association with alcohol consumption (relative rate compared with non-drinkers 1.34 (95\% confidence interval 1.14 to 1.58) for 15-21 units a week, 1.49 (1.27 to 1.75$)$ for 22-34 units, 1.74 (1.47 to 2.06) for 35 or more units). Adjustment for risk factors attenuated the increased relative risks, but they remained significantly above 1 for men drinking 22 or more units a week. There was no strong relation between alcohol consumption and mortality from coronary heart disease after adjustment. A strong positive relation was seen between alcohol consumption and risk of mortality from stroke, with men drinking 35 or more units having double the risk of non-drinkers, even after adjustment.

Conclusions The overall association between alcohol consumption and mortality is unfavourable for men drinking over 22 units a week, and there is no clear evidence of any protective effect for men drinking less than this.

\section{Introduction}

There have been numerous studies investigating the effects of alcohol consumption on mortality. The relation with all cause mortality is usually reported as $\mathrm{U}$ or $\mathrm{J}$ shaped, with moderate consumers having the lowest risk of mortality and high consumers the highest. ${ }^{1-3}$ Non-drinkers are generally found to have a mortality between that of the moderate and high consumers. There may be problems with selection bias related to health in these studies, however, as sick people may not drink because of their illness, leading to an apparent increased risk of mortality among non-drinkers.

Moderate consumption of alcohol may protect against coronary heart disease, but whether this is true for all types of alcohol or just for wine is unclear. ${ }^{4-7}$ Risk of mortality from stroke has shown variable associations with alcohol consumption.
We have performed a 21 year follow up study of working men who reported their alcohol consumption, with detailed information on risk factors which might act as confounders, including socioeconomic variables, which have generally not been adequately controlled for in previous studies. ${ }^{48}$

\section{Methods}

The analysis was based on a cohort of 5766 employed men recruited from various workplaces in Glasgow, Clydebank, and Grangemouth in Scotland between 1970 and 1973 when they were aged 35-64 years. Full details of the study have been reported elsewhere. ${ }^{9} \mathrm{~A}$ questionnaire was completed by each participant, followed by a screening examination. Weekly reported alcohol consumption was categorised by spirits, beer, and wine. This was converted to units of alcohol by taking one measure of spirits as 1 unit, 1 pint (about $1 / 2$ litre) of beer as 2 units, and one bottle of wine as 6 units. Six categories of alcohol consumption were formed (none, 1-7, 8-14, 15-21, 22-34, and 35 or more units of alcohol a week). Social class was coded according to the registrar general's classification ${ }^{10}$ from the participant's father's and the participant's own occupations. Social class was defined as either non-manual or manual. Bronchitis was defined as persistent and infective phlegm and breathlessness. ${ }^{11}$ Angina was considered present if the definite criteria of the Rose angina questionnaire were met. ${ }^{13}$ The adjusted forced expiratory volume in 1 second $\left(\mathrm{FEV}_{1}\right)$ was defined as the actual volume as a percentage of the expected volume. $^{1415}$ Ischaemia on electrocardiogram was coded according to the Minnesota system. ${ }^{16}{ }^{17}$ Deprivation category was ascertained from the postcode of the home address at time of screening. ${ }^{18}$ In 1977 about half of the cohort (2686) returned for a repeat screening.

Deaths occurring in 21 years of follow up were identified by flagging at the NHS central register in Edinburgh. Causes of death were defined as coronary heart disease (ICD-9 (international classification of diseases, 9th revision) codes 410-414), stroke (ICD-9 codes 430-438), and alcohol related causes (ICD-9 codes 141, 143-6, 148-9, 150, 155, 161, 291, 303, 571, and 800-999). ${ }^{19}$ Insufficient information was available to classify the types of stroke.

Cox's proportional hazards models ${ }^{20}$ were used to estimate proportional hazards coefficients (PHREG in SAS). ${ }^{21}$ Diastolic blood pressure was not initially treated as a confounder because higher alcohol consumption leads to higher blood pressure and blood pressure may mediate the relation between alcohol and mortality. ${ }^{22-24}$ Tests for evidence of a quadratic trend were carried out by including units per week squared as a continuous variable. Means of continuous

\section{Department of Public Health, University of Glasgow, Glasgow G12 8RZ \\ Carole L Hart, research fellow \\ Department of Social Medicine, University of Bristol, Bristol BS8 2PR \\ George Davey Smith, \\ professor of clinical epidemiology \\ West of Scotland Cancer Surveillance Unit, University of Glasgow, Glasgow G12 8RZ David J Hole, principal epidemiologist \\ University of Michigan, School of Public Health, Department of Epidemiology, Ann Arbor, MI 48109 \\ USA \\ Victor M \\ Hawthorne, \\ professor of \\ epidemiology \\ Correspondence to: Professor Davey Smith \\ zetkin@bristol.ac.uk}

BMJ 1999;318:1725-9 
Table 1 Age adjusted means and age adjusted proportions (\%) of characteristics by units of alcohol consumed a week

\begin{tabular}{|c|c|c|c|c|c|c|c|c|}
\hline Characteristic & None & $1-7$ & $8-14$ & $15-21$ & $22-34$ & $\geqslant 35$ & $\begin{array}{l}\text { P value for } \\
\text { difference* }^{*}\end{array}$ & $\begin{array}{l}P \text { value } \\
\text { for trendt }\end{array}$ \\
\hline Age (years) & 49.0 & 48.0 & 47.9 & 48.0 & 47.7 & 47.6 & 0.0001 & 0.26 \\
\hline $\begin{array}{l}\text { No (\%) with fathers with manual } \\
\text { occupation }\end{array}$ & $1346(74.8)$ & $748(68.4)$ & $764(73.1)$ & $492(80.3)$ & $511(83.2)$ & $422(85.1)$ & 0.44 & 0.0001 \\
\hline No of siblings & 3.2 & 3.0 & 3.5 & 3.7 & 3.9 & 4.3 & 0.0001 & 0.0001 \\
\hline No $(\%)$ in deprivation category 6 and 7 & $452(24.2)$ & $219(19.8)$ & $296(28.1)$ & $218(34.8)$ & $240(38.7)$ & $222(43.7)$ & 0.0001 & 0.0001 \\
\hline No $(\%)$ of car users & $991(54.6)$ & $716(64.1)$ & $587(54.7)$ & $288(45.6)$ & $257(40.4)$ & $149(29.5)$ & 0.020 & 0.0001 \\
\hline Cholesterol (mmol/l) & 5.85 & 5.94 & 5.94 & 5.81 & 5.83 & 5.88 & 0.28 & 0.13 \\
\hline Systolic blood pressure $(\mathrm{mm} \mathrm{Hg})$ & 133.1 & 131.4 & 133.6 & 135.4 & 135.1 & 140.2 & 0.37 & 0.0001 \\
\hline Diastolic blood pressure $(\mathrm{mm} \mathrm{Hg})$ & 83.4 & 82.7 & 83.5 & 84.5 & 84.5 & 87.3 & 0.11 & 0.0001 \\
\hline Body mass index $\left(\mathrm{kg} / \mathrm{m}^{2}\right)$ & 25.2 & 25.0 & 25.1 & 25.1 & 25.3 & 25.5 & 0.32 & 0.0001 \\
\hline No of cigarettes/day§ & 18.0 & 18.5 & 18.6 & 19.6 & 19.4 & 21.4 & 0.0001 & 0.0001 \\
\hline No (\%) with angina & $115(6.0)$ & $64(5.9)$ & $53(5.1)$ & $48(7.7)$ & $45(7.0)$ & $33(6.7)$ & 0.89 & 0.07 \\
\hline No (\%) with ischaemia on ECG & $106(5.5)$ & $70(6.3)$ & $52(5.0)$ & $46(7.4)$ & $28(4.6)$ & $32(6.4)$ & 0.98 & 0.39 \\
\hline No (\%) with bronchitis & $28(1.4)$ & $14(1.3)$ & $24(2.4)$ & $17(2.7)$ & $14(2.2)$ & $30(6.0)$ & 0.017 & 0.0001 \\
\hline Adjusted $\mathrm{FEV}_{1}(\%)$ ף & 95.9 & 96.2 & 93.8 & 92.2 & 92.3 & 90.0 & 0.0001 & 0.0001 \\
\hline
\end{tabular}

*Test for difference for any drinking versus none; $t$ test for continuous variables, $\chi^{2}$ test for discrete variables.

$\dagger$ Test for trend within any units of alcohol groups with continuous variable.

fFor 5300 who fasted and were not diabetic.

$\S$ For current smokers only.

१Forced expiratory volume in 1 second (\%)

variables were standardised for age with PROC GLM. Proportions of categorical variables were age standardised by the direct method, with the study population as the standard. Measures of correlation (Pearson's correlation coefficient and Cronbach's coefficent $\alpha$ ) between the initial and repeat screenings were calculated with PROC CORR.

\section{Results}

Table 1 shows that $32 \%$ of men (1833) said that they did not usually drink alcohol. This category headed "none" consists of lifetime abstainers, occasional drinkers, former drinkers, and possibly men not admitting to drinking alcohol. The non-drinkers were older, less likely to be in manual occupations or live in deprived areas, had fewer siblings, and were more likely to be car users than drinkers. There were fewer cigarette smokers among non-drinkers and the smokers used fewer cigarettes a day. Non-drinkers had lower concentrations of triglycerides, less bronchitis, and better lung function than drinkers.

Among men who consumed alcohol, higher intake was associated with worse social circumstances. Alcohol consumption showed graded associations with blood pressure, body mass index, triglyceride concentrations, bronchitis, poor lung function, proportion of smokers, and amount smoked.

\section{Follow up}

Pearson's correlation coefficient and Cronbach's $\alpha$ were calculated for the reported alcohol consumption of the 2686 men who were screened twice, giving 0.78 and 0.88 , respectively, which suggests reliable reporting and stable consumption.

In the 21 years there were 1643 deaths, including 625 from coronary heart disease, 133 from stroke, and 108 from alcohol related causes. Men who drank over
15 units of alcohol a week had significantly higher risks of dying from all causes than the non-drinkers (table 2). Those drinking over 35 units a week had a considerably increased risk. Adjustment for other variables attenuated the risks. For the two highest categories, risks remained significantly different from those in the non-drinkers.

There was a significant overall positive association between mortality from coronary heart disease and alcohol consumption. Compared with the nondrinkers, however, there was a lower risk of mortality for the category 8-14 units a week, although this was not significant. Significantly higher rates were seen for the 15-21 category and the $\geqslant 35$ category. Adjustment for other variables essentially removed the gradient between alcohol consumption and coronary mortality.

There was a highly significant increasing trend across the drinking categories for mortality from stroke. Drinkers of more than 15 units a week had significantly higher risks than non-drinkers. Those drinking 35 or more units had over double the risk. Adjustment for other variables reduced the risks but the trend remained. There was a strong association between mortality from alcohol related diseases and drinking. Drinkers in the heaviest category were three times more likely to die of these causes than non-drinkers.

Tests for evidence of quadratic associations found significant quadratic effects for all cause $(\mathrm{P}=0.011)$ and alcohol related mortality $(\mathrm{P}=0.007)$ when we adjusted for age. When adjustments were made for the other risk factors, the quadratic term was not significant for all cause mortality $(\mathrm{P}=0.2)$, although there were significant quadratic effects for alcohol related mortality $(\mathrm{P}=0.021)$. There were no significant quadratic effects for mortality from coronary heart disease or stroke. 
Table 2 Relative rates of mortality over 21 years by units of alcohol consumed a week. Figures are relative risks (95\% confidence interval) adjusted for various factors

\begin{tabular}{|c|c|c|c|c|c|c|c|c|}
\hline $\begin{array}{l}\text { Mortality and } \\
\text { adjustment for } \\
\text { relative risk }\end{array}$ & None & $1-7$ & $8-14$ & $15-21$ & $22-34$ & $\geqslant 35$ & $\begin{array}{l}\text { P value for any } \\
\text { drinking } v \text { none }\end{array}$ & $\begin{array}{l}P \text { value for trend } \\
\text { consumptiont }\end{array}$ \\
\hline \multicolumn{9}{|l|}{ All cause } \\
\hline No of deaths & 498 & 281 & 267 & 199 & 212 & 186 & & \\
\hline Adjustment A & 1 & $1.00(0.87$ to 1.16$)$ & $1.02(0.88$ to 1.18$)$ & 1.34 (1.14 to 1.58$)$ & 1.49 (1.27 to 1.75$)$ & 1.74 (1.47 to 2.06$)$ & 0.0003 & 0.0001 \\
\hline Adjustment B & 1 & 1.03 (0.89 to 1.19$)$ & 0.95 (0.81 to 1.10$)$ & 1.12 (0.95 to 1.32$)$ & 1.24 (1.05 to 1.46$)$ & 1.33 (1.12 to 1.59$)$ & 0.12 & 0.0006 \\
\hline Adjustment C & 1 & 1.03 (0.89 to 1.20$)$ & 0.93 (0.80 to 1.08$)$ & 1.10 (0.93 to 1.29$)$ & 1.22 (1.03 to 1.44$)$ & 1.25 (1.05 to 1.50$)$ & 0.22 & 0.006 \\
\hline \multicolumn{9}{|c|}{ Coronary heart disease } \\
\hline No of deaths & 198 & 122 & 91 & 79 & 72 & 63 & & \\
\hline Adjustment A & 1 & 1.09 (0.87 to 1.37$)$ & 0.87 (0.68 to 1.11$)$ & 1.33 (1.02 to 1.72$)$ & 1.26 (0.96 to 1.65$)$ & 1.46 (1.10 to 1.94$)$ & 0.15 & 0.010 \\
\hline Adjustment B & 1 & 1.13 (0.90 to 1.42$)$ & 0.81 (0.63 to 1.05$)$ & 1.09 (0.83 to 1.42$)$ & 1.04 (0.79 to 1.37$)$ & 1.08 (0.80 to 1.45$)$ & 0.86 & 0.99 \\
\hline Adjustment C & 1 & 1.13 (0.90 to 1.42$)$ & 0.79 (0.61 to 1.01$)$ & 1.06 (0.81 to 1.38$)$ & $1.01(0.77$ to 1.34$)$ & 1.00 (0.75 to 1.35$)$ & 0.91 & 0.69 \\
\hline \multicolumn{9}{|l|}{ Stroke } \\
\hline No of deaths & 38 & 20 & 21 & 19 & 18 & 17 & & \\
\hline Adjustment A & 1 & 0.98 (0.57 to 1.69$)$ & 1.13 (0.66 to 1.92$)$ & 1.80 (1.04 to 3.12 ) & 1.81 (1.03 to 3.17 ) & 2.33 (1.31 to 4.14$)$ & 0.07 & 0.0005 \\
\hline Adjustment B & 1 & 0.98 (0.57 to 1.69$)$ & $1.08(0.63$ to 1.85$)$ & 1.53 (0.87 to 2.68$)$ & 1.59 (0.89 to 2.82$)$ & 1.98 (1.09 to 3.59$)$ & 0.19 & 0.006 \\
\hline Adjustment C & 1 & 0.96 (0.55 to 1.65$)$ & $1.02(0.59$ to 1.75$)$ & 1.46 (0.84 to 2.57$)$ & 1.56 (0.88 to 2.79$)$ & 1.67 (0.91 to 3.06$)$ & 0.31 & 0.013 \\
\hline \multicolumn{9}{|c|}{ Alcohol related causes } \\
\hline No of deaths & 21 & 14 & 17 & 17 & 21 & 18 & & \\
\hline Adjustment A & 1 & 1.15 (0.58 to 2.26$)$ & $1.47(0.78$ to 2.80$)$ & 2.60 (1.37 to 4.93$)$ & 3.31 (1.81 to 6.07$)$ & 3.72 (1.98 to 7.00$)$ & 0.003 & 0.0001 \\
\hline Adjustment B & 1 & 1.20 (0.61 to 2.37$)$ & 1.39 (0.73 to 2.64$)$ & 2.25 (1.18 to 4.31$)$ & 2.78 (1.49 to 5.17$)$ & 2.94 (1.52 to 5.68 ) & 0.012 & 0.013 \\
\hline \multicolumn{9}{|c|}{ 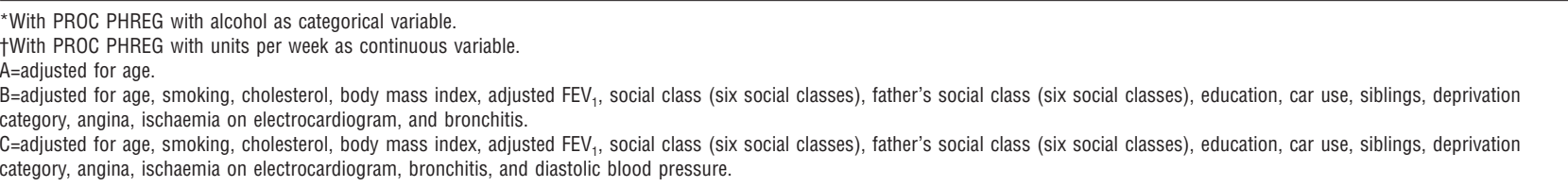 } \\
\hline
\end{tabular}

\section{Discussion}

We have shown that in this cohort there was no robust relation between consumption of alcohol and mortality from coronary heart disease, but there was a strong positive relation between consumption and mortality from stroke. Unlike other studies ${ }^{1-32526}$ we found no strong evidence that alcohol consumption reduced all cause mortality for light and moderate drinkers. While there was a suggestion of a J shaped relation because of the slightly lower risk of mortality for men drinking 8-14 units, this was a small effect and not reflected in the risk in those who drank 1-7 units, who also fall into the "moderate drinking" category. Our study population of working men would exclude men unable to work because of ill health. Shaper has suggested that the higher risk of mortality seen in nondrinkers is caused in part by the inclusion of men with existing disease, who may have been former drinkers, into the categories of non-drinkers. ${ }^{27}$ Our nondrinking category probably contained fewer men who had stopped drinking because of ill health than in general population studies and this may be why the $\mathrm{U}$ or $\mathrm{J}$ shaped relations were not evident.

\section{Coronary heart disease mortality}

Numerous studies of the relation between mortality from coronary heart disease and alcohol consumption exist, with many finding a reduction in such mortality with moderate consumption. ${ }^{1562829}$ The current study showed a non-significant lower risk of mortality from coronary heart disease for one moderate alcohol consumption group, but again the findings were inconsistent. The increased risks for drinkers of 15 units or more were attenuated by adjustments for risk factors, which shows the importance of potential confounding factors. Additional adjustment for diastolic blood pres- sure reduced the risks further, particularly among those in the heaviest drinking category, indicating that excessive alcohol consumption may have a detrimental effect on risk of mortality from coronary heart disease through increased blood pressure.

\section{Stroke mortality}

Studies on the relation between alcohol consumption and mortality from stroke have produced contradictory findings, perhaps because the relations are different for haemorrhagic and ischaemic stroke. The risk of haemorrhagic stroke is thought to increase with alcohol consumption, ${ }^{3031}$ whereas some studies have found a reduced risk of ischaemic stroke for moderate drinkers $^{32}$ and either an increased risk ${ }^{3132}$ or no effect ${ }^{30}$ for heavy drinkers. As about $85 \%$ of strokes in adults in Great Britain are due to cerebral thrombosis and infarction most deaths from stroke in the current study are likely to have been ischaemic. ${ }^{233}$

Studies in China, ${ }^{6}$ the United Kingdom, ${ }^{1}$ and $\mathrm{Japan}^{31}$ have found increased risk of mortality from stroke with amount of alcohol consumed. J shaped relations have also been found. ${ }^{3134}$ Conversely, the cancer prevention II study found the highest risk of mortality from stroke in non-drinkers, with a flat relation with increasing amounts of alcohol consumed..$^{29}$ Another study found non-drinkers to have a higher risk of stroke, but this disappeared after adjustment for obesity and exercise. ${ }^{35}$ A study of fatal and non-fatal stroke found a non-significant increased risk in lifetime abstainers compared with occasional drinkers and an increased risk of stroke for the heaviest category of drinkers. ${ }^{23}$ The current study shows a clear gradient of stroke mortality and consumption of alcohol, with a twofold risk in men in the highest drinking category. Raised blood pressure as a consequence of 
drinking seems to account for much, but not all, of this association. Measurement error with respect to blood pressure may account for the residual association after adjustments for blood pressure. ${ }^{36}$

\section{Reliability of data}

Questions on alcohol consumption may not be answered accurately. In this study nearly a third of the men were classified as non-drinkers. This figure was high compared with that from the Scottish heart health study, which reported $19 \%$ non-drinkers, ${ }^{37}$ but similar to that in a study of Scottish drinking habits carried out in 1972, which reported $21 \%$ of men aged $41-50$ years and $35 \%$ of men aged $51-65$ years as nondrinkers or occasional drinkers. ${ }^{38}$ Similar results were reported by the British regional heart study $(2.8 \%$ non-drinkers, $6.9 \%$ former drinkers, and $29.7 \%$ occasional drinkers, totalling $39 \%){ }^{23}$ This is comparable with the proportion of non-drinkers in our study. The lowest risk for alcohol related causes of death for men in the non-drinking category and the increased risk with amount of alcohol consumed suggests that the answers to the questionnaire are valid. Additional evidence is given by the graded association of reported alcohol consumption with blood pressure and triglyceride concentrations, which are clearly related to alcohol intake, ${ }^{223940}$ and the high correlations between the answers to the first and second questionnaires. Given this evidence of validity of the reported alcohol data it is unlikely that our findings are due to misclassification of alcohol consumption. Therefore it is important to consider reasons for discrepancies between our results and those of some previous studies.

\section{Differences between studies}

Firstly, the inclusion of men with illnesses that lead them to be non-drinkers, and of former heavy drinkers among the non-drinking category, may be of less importance in this occupational cohort than in community based studies. Here there is an analogy with studies of the association between cholesterol concentration and mortality, where the U shaped associations are strongest in community based studies, which include individuals with low cholesterol concentrations because of illness, and weakest in healthy populations. ${ }^{4142}$ Secondly, we adjusted for socioeconomic factors and other potential confounders more completely than previous studies. As socioeconomic position in early life has an important influence on mortality from cardiovascular disease ${ }^{43}$ independent of adulthood socioeconomic position, there may be important confounding by childhood social position. In this study more favourable childhood and adulthood socioeconomic profiles were seen in the low to moderate drinkers compared with the non-drinkers or heavy drinkers. Thus considerable confounding by socioeconomic position, largely uncontrolled for in previous studies, could exist. Thirdly, recent studies have suggested that binge drinking is associated with increased cardiovascular and all cause mortality. ${ }^{44-46}$ Sources suggest a more concentrated pattern of drinking in Scotland and Northern Ireland than in England and that in Britain generally drinking to intoxication periodically is more common than drinking large amounts habitually. ${ }^{47}$ The 1972 study of Scottish drinking habits found that men who consumed 21-50 units
- Results from a large cohort study of employed Scottish men showed different relations between alcohol consumption and mortality than previous studies

- There was no relation between mortality from coronary heart disease and alcohol consumption once adjustments were made for potential confounding factors

- There was a strong relation with mortality from stroke; drinkers of over 35 units a week had double the risk of mortality compared with non-drinkers

- Some but not all of this could be accounted for by alcohol related increases in blood pressure

- Overall, risk of all cause mortality was higher in men drinking 22 or more units a week

a week on average drank on 4 days a week, suggesting binge drinking was occurring. ${ }^{38}$ Alcohol consumption may show direct associations with mortality among cohorts in which a substantial proportion of drinking consists of irregular high intake. It would thus be expected that among cohorts for whom this may not be true ${ }^{129}$ no such associations would be seen, but in cohorts in which binge drinking is relatively common (such as the current cohort) such associations would be evident. ${ }^{44}$ This hypothesis should be tested in cohorts with detailed data on drinking patterns.

\section{Conclusion}

To conclude, we have shown that in this cohort of Scottish men there is no clear relation between alcohol consumption and mortality from coronary heart disease, but there is a strong relation with risk of mortality from stroke. The overall association between alcohol consumption and mortality is unfavourable for men drinking over 22 units a week and does not support the promotion of increased drinking for reasons of health.

Contributors: GDS and DJH were responsible for obtaining funding. VMH and DJH were original investigators on the study. CLH was responsible for performing the statistical analyses, with the help of DJH. CLH wrote the first draft of the paper, and GDS, DJH, and VMH contributed to the final submitted version. DJH and GDS are guarantors for the study.

Funding: NHS Management Executive (Cardiovascular Disease and Stroke Research and Development Initiative), Chest Heart and Stroke Scotland, and the Stroke Association. Competing interests: None declared.

Doll R, Peto R, Hall E, Wheatley K, Gray R. Mortality in relation to consumption of alcohol: 13 years' observations on male British doctors. BMJ 1994:309:911-8.

2 Poikolainen K. Alcohol and mortality: a review. J Clin Epidemiol $1995 ; 48: 455-65$

3 Renaud S, Guéguen R, Schenker J, d'Houtard A. Alcohol and mortality in middle-aged men from eastern France. Epidemiology 1998;9:184-8.

4 Grønbæk M, Deis A, Sørensen T, Becker U, Schnohr P, Jensen G. Mortality associated with moderate intakes of wine, beer, or spirits. BMJ 1995:310:1165-9.

5 Rimm EB, Klatsky A, Grobbee D, Stampfer MJ. Review of moderate alcohol consumption and reduced risk of coronary heart disease: is the effect due to beer, wine, or spirits? BMJ 1996;312:731-6.

6 Yuan J, Ross RK, Gao Y, Henderson BE, Yu MC. Follow up study of moderate alcohol intake and mortality among middle aged men in Shanghai, China. BMJ 1997;314:18-23.

7 White I. The cardioprotective effects of moderate alcohol consumption. BMJ 1996;312:1179-80. 
8 Westin S. Study confounded by lack of correction for social class (letter). BMJ 1995;311:1167.

9 Davey Smith G, Hart CL, Hole D, MacKinnon P, Gillis C, Watt G, et al. Education and occupational social class: which is the more importan indicator of mortality risk? J Epidemiol Community Health 1998;52:153-60.

10 General Register Office. Classification of occupations 1966. London: HMSO, 1966.

11 Medical Research Council. Definition and classification of chronic bronchitis for epidemiological purposes. Lancet 1965;i:775-9.

12 Rose GA, Blackburn H, Gillum RF, Prineas RJ. Cardiovascular surve) methods. Geneva: World Health Organisation, 1982.

13 Hart CL, Watt GCM, Davey Smith G, Gillis CR, Hawthorne VM. Pre-existing ischaemic heart disease and ischaemic heart disease mortality in women compared with men. Int J Epidemiol 1997;26:508-15.

14 Blane D, Hart CL, Davey Smith G, Gillis CR, Hole DJ, Hawthorne VM Association of cardiovascular disease risk factors with socioeconomi position during childhood and during adulthood. BMJ 1996;313:1434-8.

15 Davey Smith G, Hart CL, Blane D, Gillis C, Hawthorne V. Lifetime socioeconomic position and mortality: prospective observational study. $B M J$ 1997;314:547-52.

16 Prineas RJ, Crow RS, Blackburn H. The Minnesota manual of electrocardiographic findings. Bristol: John Wright, 1982.

17 Hawthorne VM, Watt GCM, Hart CL, Hole DJ, Davey Smith G, Gillis CR Cardiorespiratory disease in men and women in Scotland: baseline characteristics of the Renfrew/Paisley (Midspan) study population. Scottish Med J 1995;40:102-7.

18 Carstairs V, Morris R. Deprivation and health in Scotland. Aberdeen: Aberdeen University Press, 1991

19 World Health Organisation. Classification of diseases 9 th revision. Geneva: WHO, 1977.

20 Cox D. Regression models and life tables. J R Stat Soc B 1972;34:187-200.

21 SAS Institute. SAS/STAT software: the PHREG procedure. Version 6. Cary, North Carolina: SAS Institute, 1991. (SAS Technical Report P-217.)

22 Marmot MG, Elliott P, Shipley MJ, Dyer AR, Ueshima H, Beevers G, et al. Alcohol and blood pressure: the INTERSALT study. BMJ 1994; 308:1263-7

23 Wannamethee SG, Shaper AG. Patterns of alcohol intake and risk of stroke in middle-aged British men. Stroke 1996;27:1033-9

24 Shaper AG, Wannamethee G, Whincup P. Alcohol and blood pressure in middle-aged British men. J Hum Hypertens 1988;2:71-8.

25 Brenner H, Arndt V, Rothenbacher D, Schuberth S, Fraisse E, Fliedner T The association between alcohol consumption and all-cause mortality in a cohort of male employees in the German construction industry. Int I Epidemiol 1997;26:85-91.

26 Keil U, Chambless LE, Döring A, Filipiak B, Stieber J. The relation of alcohol intake to coronary heart disease and all-cause mortality in beer-drinking population. Epidemiology 1997;8:150-6.

27 Shaper AG. Alcohol and mortality: a review of prospective studies. $\mathrm{Br} \mathrm{J}$ Addiction 1990;85:837-47.

28 Rehm JT, Bondy SJ, Sempos CT, Vuong CV. Alcohol consumption and coronary heart disease morbidity and mortality. Am J Epidemiol 1997; 146:495-501.

29 Thun MJ, Peto R, Lopez AD, Monaco JH, Henley SJ, Heath CW, Doll R. Alcohol consumption and mortality among middle-aged and elderly US adults. N Engl J Med 1997;337:1705-14
30 Stampfer MJ, Colditz GA, Willett WC, Speizer FE, Hennekens CH. A prospective study of moderate alcohol consumption and the risk of coronary disease and stroke in women. N Engl J Med 1988;319:267-73.

31 Iso H, Kitamura A, Shimamoto T, Sankai T, Naito Y, Sato S, et al. Alcoho intake and the risk of cardiovascular disease in middle-aged Japanese men. Stroke 1995;26:767- 73

32 Palomäki H, Kaste M. Regular light-to-moderate intake of alcohol and the risk of ischemic stroke. Is there a beneficial effect? Stroke 1993;24:1828-32.

33 Sandercock PAG, Warlow CP, Jones LN, Starkey IR. Predisposing factors for cerebral infarction: the Oxfordshire community stroke project. $B M J$ 1989;298:75-80

34 Gill JS, Shipley MJ, Tsementzis SA, Hornby RS, Gill SK, Hitchcock ER, et al. Alcohol consumption-a risk factor for hemorrhagic and nonhemorrhagic stroke. Am J Med 1991;90:489-97.

35 Shinton R, Sagar G, Beevers G. The relation of alcohol consumption to cardiovascular risk factors and stroke. The west Birmingham stroke project. J Neurol Neurosurg Psychiatry 1993;56:458-62.

36 Davey Smith G, Phillips AN. Confounding in epidemiological studies: why "independent" effects may not be all they seem. BMJ 1992;305:757-9

37 Woodward M, Tunstall-Pedoe H. Alcohol consumption, diet, coronary risk factors and prevalent coronary heart disease in men and women in the Scottish heart health study. J Epidemiol Community Health 1995;49:354-62.

38 Dight SE. Scottish drinking habits. London: HMSO, 1976

39 Smit JWA, Wijnne HJA, Schobben F, Sitsen A, De Bruin TWA, Erkelens DW. Effects of alcohol consumption on pharmacokinetics, efficacy, and safety of fluvastatin. Am J Cardiol 1995;76:89-96A.

40 Choudhury SR, Ueshima H, Kita Y, Kobayashi KM, Okayama A, Yamakawa M, et al. Alcohol intake and serum lipids in a Japanese population. Int J Epidemiol 1994;23:940-7.

41 Davey Smith G, Shipley M, Marmot MG, Rose G. Plasma cholesterol concentration and mortality: the Whitehall study. JAMA 1992;267:70-6.

42 Hole D, Davey Smith G, Watt GCM, Hart CL, Gillis CR, Hawthorne VM. Low cholesterol and mortality: demonstration of a health selection effect. J Epidemiol Community Health 1993;47:402.

43 Davey Smith G, Hart C, Blane D, Hole D. Adverse socioeconomic conditions in childhood and cause specific adult mortality: prospective observational study. $B M J$ 1998;316:1631-5.

44 Kauhanen J, Kaplan GA, Goldberg DE, Salonen JT. Beer bingeing and mortality: results from the Kuopio ischaemic heart disease risk factor study, a prospective population based study. BMJ 1997;315:846-51.

45 Kauhanen J, Kaplan GA, Goldberg DD, Cohen RD, Lakka TA, Salonen JT. Frequent hangovers and cardiovascular mortality in middle-aged men. Epidemiology 1997;8:310-4

46 McKee M, Britton A. The positive relationship between alcohol and heart disease in eastern Europe: potential physiological mechanisms. $J R S o c$ Med 1998;91:402-7.

47 Office for National Statistics. The health of adult Britain 1841-1994. London: Stationery Office, 1997.

(Accepted 18 February 1999)

\section{A salutary lesson \\ Three very unwise men}

Three men sharing accommodation decided to make a fresh vegetable salad, and the oldest convinced his junior flatmates that a plant growing in the back garden was Russian comfrey. Having made the salad the senior member ate three mouthfuls of the salad and then desisted because of the disagreeable taste. The second ate only one mouthful, and the junior member ate little at all because of the unpleasant taste. The two senior members started to feel ill within six hours and at this point the ringleader revised his opinion about the Russian comfrey and decided it was foxglove (Digitalis purpurea).

Help was sought at the accident and emergency department, where they were examined and found to be well enough to go home. However, the two men were admitted to hospital the next day, both complaining of nausea, vomiting, and irregular slow heart rates. The junior member was admitted a little later on the same day with gross anxiety and similar but less marked symptoms.

The senior diner, who had ingested the most comfrey/foxglove, had a complicated electrocardiogram featuring a high grade atrioventricular block, runs of idionodal tachycardia, and an accelerated idionodal rhythm. There was also some aberrant conduction (right bundle branch block pattern) and atrioventricular nodal escape beats. Digitalis effect was also noted.
The middle member of the group had an electrocardiogram which showed first degree and second degree sinoatrial block with occasional atrioventricular nodal escape beats and changes compatible with digitalis effect. The junior member of the group had a normal electrocardiogram with sinus bradycardia (rate 46). None of these three men were on prescribed medication at the time of their admission. All three were shown to have modest (low therapeutic range) serum digoxin concentrations; the other presumed metabolites of digitalis were unable to be measured.

The two older patients were monitored and treated with forced diuresis, potassium supplementation, and frusemide. Atropine and phenytoin were considered but not used. When their symptoms persisted they were treated by peritoneal dialysis. Both recovered slowly over the next few days, probably due to the natural excretion of the digitalis metabolites rather than the specific treatments given. The junior member of the flat required no treatment and recovered spontaneously. These three very unwise but adventurous gourmets spent 12, nine, and six days respectively in hospital, and each went home better informed about the difference between foxglove and Russian comfrey.

B M Colls, physician, Christchurch Hospital, New Zealand 